\title{
Convergence theorems for generalized asymptotically quasi-nonexpansive mappings in cone metric spaces
}

\author{
G. S. SAluja \\ Department of Mathematics and Information Technology, \\ Govt. Nagarjuna P.G. College of Science, \\ Raipur - 492010 (C.G.), India. \\ saluja_1963@rediffmail.com, saluja1963@gmail.com
}

\begin{abstract}
The purpose of this paper is to study an Ishikawa type iteration process with errors to approximate the common fixed point of two generalized asymptotically quasinonexpansive mappings in the framework of cone metric spaces. Our results extend and generalize many known results from the existing literature.
\end{abstract}

\section{RESUMEN}

El propósito de este artículo es estudiar el proceso de iteración del tipo Ishikawa con errores para aproximar el puto fijo común de dos aplicaciones cuasi-expansivas asintóticamente generalizadas en el marco de espacios métricos cónicos. Nuestro resultado extiende y generaliza muchos resultados de la literatura existente.

Keywords and Phrases: Generalized asymptotically quasi-nonexpansive mapping, common fixed point, Ishikawa type iteration process with errors, cone metric space, normal and non-normal cone.

2010 AMS Mathematics Subject Classification: 47H10, 54H25. 


\section{Introduction and Preliminaries}

The Well-known Banach contraction principle and its several generalization in the setting of metric spaces play a central role for solving many problems of nonlinear analysis. For example, see $[2,6,7,20,21]$.

In 1980, Rzepecki [23] introduced a generalized metric by replacing the set of real numbers with normal cone of the Banach space. In 1987, Lin [17] introduced the notion of K-metric spaces by replacing the set of real numbers with cone in the metric function. Zabrejko [33] studied new revised version of the fixed point theory in K-metric and K-normed linear spaces by replacing an ordered Banach space instead of the set of real numbers, as the co-domain for a metric. Ordered normed spaces and cones have applications in applied mathematics, for instance, in using Newton's approximations method [28,33], and in optimization theory [7].

Recently, Huang and Zhang [10] used the notion of cone metric spaces as a generalization of metric spaces. They have replaced the real numbers (as the co-domain of a "metric") by an ordered Banach space. The authors described the convergence in cone metric spaces and introduced their completeness. Then they proved some fixed point theorems for contractive single-valued mappings in such spaces. In their theorems cone is normal. For more fixed point results in cone metric spaces, see [1, 3, 11, 24, 25, 32.

Most recently, Dukic et al. [8] studied an Ishikawa type iteration process with errors for two uniformly quasi-Lipschitzian mappings in complete convex cone metric spaces and they gave a necessary and sufficient condition to approximate the common fixed point for said mappings. Their results extended and generalized many known results from the literature.

The main goal of this paper is to study an Ishikawa type iteration process with errors for two generalized asymptotically quasi-nonexpansive mappings in the setting of complete convex cone metric spaces and also give a necessary and sufficient condition to approximate the common fixed point for said mappings. The results presented in this paper extend and generalize many known results from the literature.

Consistent with [7] and [10, the following definitions and results will be needed in the sequel.

Let $E$ be a real Banach space. A subset $P$ of $E$ is called a cone whenever the following conditions hold:

$\left(\mathrm{C}_{1}\right) \mathrm{P}$ is closed, nonempty and $\mathrm{P} \neq\{0\}$; 
$\left(C_{2}\right) a, b \in \mathbb{R}, a, b \geq 0$ and $x, y \in P$ imply $a x+b y \in P$

$\left(C_{3}\right) P \cap(-P)=\{0\}$

Given a cone $\mathrm{P} \subset \mathrm{E}$, we define a partial ordering $\preceq$ with respect to $\mathrm{P}$ by $\mathrm{x} \preceq \mathrm{y}$ if and only if $y-x \in P$. We shall write $x \prec y$ to indicate that $x \preceq y$ but $x \neq y$, while $x \ll y$ will stand for $y-x \in$ int $P$ (interior of $P$ ). If intP $\neq \emptyset$ then $P$ is called a solid cone (see [28]).

There exist two kinds of cones: normal (with the normal constant k) and non-normal ones [7]).

Let $E$ be a real Banach space, $P \subset E$ a cone and $\preceq$ partial ordering defined by $P$. Then $P$ is called normal if there is a number $k>0$ such that for all $x, y \in P$,

$$
0 \preceq x \preceq y \text { imply }\|x\| \leq k\|y\|,
$$

or equivalently, if $(\forall n) x_{n} \preceq y_{n} \preceq z_{n}$ and

$$
\lim _{n \rightarrow \infty} x_{n}=\lim _{n \rightarrow \infty} z_{n}=x \text { imply } \lim _{n \rightarrow \infty} y_{n}=x .
$$

The least positive number $k$ satisfying (11) is called the normal constant of $P$. It is clear that $k \geq 1$.

Example 1.1. (see [28]) Let $E=C_{\mathbb{R}}^{1}[0,1]$ with $\|x\|=\|x\|_{\infty}+\left\|x^{\prime}\right\|_{\infty}$ on $P=\{x \in E: x(t) \geq 0\}$. This cone is not normal. Consider, for example, $x_{n}(t)=\frac{t^{n}}{n}$ and $y_{n}(t)=\frac{1}{n}$. Then $0 \preceq x_{n} \preceq y_{n}$, and $\lim _{n \rightarrow \infty} y_{n}=0$, but $\left\|x_{n}\right\|=\max _{t \in[0,1]}\left|\frac{t^{n}}{n}\right|+\max _{t \in[0,1]}\left|t^{n-1}\right|=\frac{1}{n}+1>1$; hence $x_{n}$ does not converge to zero. It follows by (2) that $\mathrm{P}$ is a non-normal cone.

Definition 1.1. (see [10,33]) Let $X$ be a nonempty set. Suppose that the mapping $d: X \times X \rightarrow$ E satisfies:

$\left(d_{1}\right) 0 \preceq d(x, y)$ for all $x, y \in X$ and $d(x, y)=0$ if and only if $x=y$;

$\left(d_{2}\right) d(x, y)=d(y, x)$ for all $x, y \in X$;

$\left(d_{3}\right) d(x, y) \preceq d(x, z)+d(z, y) x, y, z \in X$. 
Then $\mathrm{d}$ is called a cone metric [10] or K-metric [33] on $X$ and $(X, d)$ is called a cone metric [10] or K-metric space [33] (we shall use the first term).

The concept of a cone metric space is more general than that of a metric space, because each metric space is a cone metric space where $\mathrm{E}=\mathbb{R}$ and $\mathrm{P}=[0,+\infty)$.

Example 1.2. (see [10]) Let $E=\mathbb{R}^{2}, P=\left\{(x, y) \in \mathbb{R}^{2}: x \geq 0, y \geq 0\right\}, X=\mathbb{R}$ and $d: X \times X \rightarrow E$ defined by $d(x, y)=(|x-y|, \alpha|x-y|)$, where $\alpha \geq 0$ is a constant. Then $(X, d)$ is a cone metric space with normal cone $\mathrm{P}$ where $\mathrm{k}=1$.

Example 1.3. (see [24]) Let $E=\ell^{2}, P=\left\{\left\{x_{n}\right\}_{n \geq 1} \in E: x_{n} \geq 0\right.$, for all $\left.n\right\},(X, \rho)$ a metric space, and $d: X \times X \rightarrow E$ defined by $d(x, y)=\left\{\rho(x, y) / 2^{\mathfrak{n}}\right\}_{\mathfrak{n} \geq 1}$. Then $(X, d)$ is a cone metric space.

Clearly, the above examples show that the class of cone metric spaces contains the class of metric spaces.

Definition 1.2. (see [10]) Let $(X, d)$ be a cone metric space. We say that $\left\{x_{n}\right\}$ is:

(i) a Cauchy sequence if for every $\varepsilon$ in $E$ with $0 \ll \varepsilon$, then there is an $N$ such that for all $n, m>N, d\left(x_{n}, x_{m}\right) \ll \varepsilon ;$

(ii) a convergent sequence if for every $\varepsilon$ in $E$ with $0 \ll \varepsilon$, then there is an $N$ such that for all $n>N, d\left(x_{n}, x\right) \ll \varepsilon$ for some fixed $x$ in $X$.

A cone metric space $X$ is said to be complete if every Cauchy sequence in $X$ is convergent in $\mathrm{X}$.

Let us recall ( [10]) that if $P$ is a normal solid cone, then $x_{n} \in X$ is a Cauchy sequence if and only if $\left\|d\left(x_{n}, x_{m}\right)\right\| \rightarrow 0$ as $n, m \rightarrow \infty$. Further, $x_{n} \in X$ converges to $x \in X$ if and only if $\left\|\mathrm{d}\left(\mathrm{x}_{\mathrm{n}}, \mathrm{x}\right)\right\| \rightarrow 0$ as $\mathrm{n} \rightarrow \infty$.

In the sequel we assume that $E$ is a real Banach space and that $P$ is a normal solid cone in $E$, that is, normal cone with intP $\neq \emptyset$. The last assumption is necessary in order to obtain reasonable results connected with convergence and continuity. The partial ordering induced by the cone $\mathrm{P}$ will be denoted by $\preceq$. 


\section{Convexity in cone metric space}

Let $(X, d)$ be a cone metric space with solid cone $P$ and $T: X \rightarrow X$ a given mapping. Let $F(T)$ denote the set of fixed points of $\mathrm{T}$.

Definition 2.1. (1) The mapping $T$ is said to be nonexpansive if

$$
\mathrm{d}(\mathrm{Tx}, \mathrm{Ty}) \preceq \mathrm{d}(x, y)
$$

for all $x, y \in X$.

(2) The mapping $T$ is said to be quasi-nonexpansive if $F(T) \neq \emptyset$ and

$$
d(T x, p) \preceq d(x, p)
$$

for all $x \in X$ and $p \in F(T)$.

(3) The mapping $T$ is said to be asymptotically nonexpansive if there exists a sequence $\left\{r_{n}\right\} \in[0, \infty)$ with $r_{n} \rightarrow 0$ as $n \rightarrow \infty$ such that

$$
d\left(T^{n} x, T^{n} y\right) \preceq\left(1+r_{n}\right) d(x, y)
$$

for all $x, y \in X$.

(4) The mapping $T$ is said to be asymptotically quasi-nonexpansive if $F(T) \neq \emptyset$ and there exists a sequence $\left\{r_{n}\right\} \in[0, \infty)$ with $r_{n} \rightarrow 0$ as $n \rightarrow \infty$ such that

$$
d\left(T^{n} x, p\right) \preceq\left(1+r_{n}\right) d(x, p)
$$

for all $x \in X$ and $p \in F(T)$.

(5) The mapping $T$ is said to be generalized asymptotically quasi-nonexpansive [12] if $F(T) \neq \emptyset$ and there exist two sequences of real numbers $\left\{r_{n}\right\}$ and $\left\{s_{n}\right\} \in[0, \infty)$ with $r_{n} \rightarrow 0$ and $s_{n} \rightarrow 0$ as $n \rightarrow \infty$ such that

$$
d\left(T^{n} x, p\right) \preceq\left(1+r_{n}\right) d(x, p)+s_{n},
$$


for all $x \in X$ and $p \in F(T)$.

(6) The mapping $T$ is said to be uniformly L-Lipschitzian if there exists a constant $L>0$ such that

$$
d\left(T^{n} x, T^{n} y\right) \preceq L d(x, y),
$$

for all $x, y \in X$.

Remark 2.1. (i) It is clear that the nonexpansive mappings with the nonempty fixed point set $\mathrm{F}(\mathrm{T})$ are quasi-nonexpansive.

(ii) The linear quasi-nonexpansive mappings are nonexpansive, but it is easily seen that there exist nonlinear continuous quasi-nonexpansive mappings which are not nonexpansive; for example, define $T(x)=(x / 2) \sin (1 / x)$ for all $x \neq 0$ and $T(0)=0$ in $\mathbb{R}$.

(iii) It is obvious that if $\mathrm{T}$ is nonexpansive, then it is asymptotically nonexpansive with the constant sequence $\{1\}$.

(iv) If $\mathrm{T}$ is asymptotically nonexpansive, then it is uniformly Lipschitzian with the uniform Lipschitz constant $L=\sup \left\{1+r_{n}: n \geq 1\right\}$. However, the converse of this claim is not true.

(v) If in definition (5), $s_{\mathfrak{n}}=0$ for all $n \in \mathbb{N}$, then $T$ becomes asymptotically quasi-nonexpansive, and hence the class of generalized asymptotically quasi-nonexpansive maps includes the class of asymptotically quasi-nonexpansive maps.

In recent years, asymptotically nonexpansive mappings, asymptotically nonexpansive type mappings, asymptotically quasi-nonexpansive mappings and asymptotically quasi-nonexpansive type mappings have been studied extensively in the setting of convex metric spaces (see e.g. [5, $9,14-16,18,19,27])$.

In 1970, Takahashi [26] introduced the concept of convexity in a metric space and the properties of the space.

Definition 2.2. (see [26]) Let $(X, d)$ be a metric space and $I=[0,1]$. A mapping $W: X \times X \times$ $\mathrm{I} \rightarrow \mathrm{X}$ is said to be a convex structure on $\mathrm{X}$ if for each $(x, y, \lambda) \in X \times X \times I$ and $u \in X$,

$$
d(u, W(x, y, \lambda)) \leq \lambda d(u, x)+(1-\lambda) d(u, y)
$$


$X$ together with a convex structure $W$ is called a convex metric space, denoted by $(X, d, W)$. A nonempty subset $K$ of $X$ is said to be convex if $W(x, y, \lambda) \in K$ for all $(x, y, \lambda) \in K \times K \times I$.

Remark 2.2. Every normed space is a convex metric space, where a convex structure $W(x, y, z ; \alpha, \beta, \gamma)=\alpha x+\beta y+\gamma z$, for all $x, y, z \in E$ and $\alpha, \beta, \gamma \in I$ with $\alpha+\beta+\gamma=1$. In fact,

$$
\begin{aligned}
\mathrm{d}(\mathrm{u}, W(x, y, z ; \alpha, \beta, \gamma)) & =\|\mathfrak{u}-(\alpha x+\beta \mathrm{y}+\gamma z)\| \\
& \leq \alpha\|\mathrm{u}-x\|+\beta\|\mathrm{u}-\mathrm{y}\|+\gamma\|\mathrm{u}-z\| \\
& =\alpha \mathrm{d}(\mathfrak{u}, \mathrm{x})+\beta \mathrm{d}(\mathfrak{u}, \mathrm{y})+\gamma \mathrm{d}(\mathfrak{u}, z), \quad \forall \mathfrak{u} \in \mathrm{X} .
\end{aligned}
$$

But there exists some convex metric spaces which can not be embedded into normed space.

Now we define the following:

Definition 2.3. Let $(X, d)$ be a cone metric space and $I=[0,1]$. A mapping $W: X \times X \times I \rightarrow X$ is said to be a convex structure on $X$ if for any $(x, y, \lambda) \in X \times X \times I$ and $u \in X$, the following inequality holds:

$$
d(u, W(x, y, \lambda)) \preceq \lambda d(u, x)+(1-\lambda) d(u, y) .
$$

If $(X, d)$ be a cone metric space with a convex structure $W$, then $(X, d)$ is called a convex abstract metric space or convex cone metric space (see also [13], [22]). Moreover, a nonempty subset $C$ of $X$ is said to be convex if $W(x, y, \lambda) \in C$, for all $(x, y, \lambda) \in C \times C \times I$.

Definition 2.4. Let $(X, d)$ be a cone metric space, $I=[0,1]$ and $\left\{a_{n}\right\},\left\{b_{n}\right\},\left\{c_{n}\right\}$ are real sequences in $[0,1]$ with $a_{n}+b_{n}+c_{n}=1$. A mapping $W: X^{3} \times I^{3} \rightarrow X$ is said to be a convex structure on $X$ if for any $\left(x, y, z, a_{n}, b_{n}, c_{n}\right) \in X^{3} \times I^{3}$ and $u \in X$, the following inequality holds:

$$
d\left(u, W\left(x, y, z, a_{n}, b_{n}, c_{n}\right)\right) \preceq a_{n} d(u, x)+b_{n} d(u, y)+c_{n} d(u, z) .
$$

If $(X, d)$ be a cone metric space with a convex structure $W$, then $(X, d)$ is called a generalized convex cone metric space. Moreover, a nonempty subset $C$ of $X$ is said to be convex if $W\left(x, y, z, a_{n}, b_{n}, c_{n}\right) \in C$, for all $\left(x, y, z, a_{n}, b_{n}, c_{n}\right) \in C^{3} \times I^{3}$.

Remark 2.3. If $E=\mathbb{R}, P=[0,+\infty),\|\|=.|$.$| , then (X, d)$ is a convex metric space, i.e., generalized convex metric space as in 30 . 
Example 2.1. Let $(X, d)$ be a cone metric space as in Example (1.2)(1). If $W(x, y, \lambda)=$ : $\lambda x+(1-\lambda) y$, then $(X, d)$ is a cone metric space. Hence, this notion is more general than that of a convex metric space.

Definition 2.5. Let $(X, d)$ be a cone metric space with a convex structure $W: X^{3} \times I^{3} \rightarrow X$, $\mathrm{S}, \mathrm{T}: \mathrm{X} \rightarrow \mathrm{X}$ be two generalized asymptotically quasi-nonexpansive mappings with sequences of real numbers $\left\{r_{n}\right\}$ and $\left\{s_{n}\right\} \in[0, \infty)$ such that $r_{n} \rightarrow 0$ and $s_{n} \rightarrow 0$ as $n \rightarrow \infty$ and $\left\{a_{n}\right\},\left\{b_{n}\right\},\left\{c_{n}\right\}$, $\left\{a_{n}^{\prime}\right\},\left\{b_{n}^{\prime}\right\},\left\{c_{n}^{\prime}\right\}$ are six sequences in [0,1] with $a_{n}+b_{n}+c_{n}=a_{n}^{\prime}+b_{n}^{\prime}+c_{n}^{\prime}=1, n=1,2, \ldots$ For any given $x_{1} \in X$, define a sequence $\left\{x_{n}\right\}$ as follows:

$$
\begin{aligned}
y_{n} & =W\left(x_{n}, S^{n} x_{n}, v_{n}, a_{n}^{\prime}, b_{n}^{\prime}, c_{n}^{\prime}\right), \\
x_{n+1} & =W\left(x_{n}, T^{n} y_{n}, u_{n}, a_{n}, b_{n}, c_{n}\right),
\end{aligned}
$$

where $\left\{u_{n}\right\},\left\{v_{n}\right\}$ are two sequences in $X$ satisfying the following condition: for any nonnegative integers $n, m, 1 \leq n<m$, if $\delta\left(A_{n m}\right)>0$, then

$$
\max _{n \leq i, j \leq m}\left\{\|d(x, y)\|: x \in\left\{u_{i}, v_{i}\right\}, y \in\left\{x_{j}, y_{j}, T y_{j}, S x_{j}, u_{j}, v_{j}\right\}\right\}<\delta\left(A_{n m}\right),
$$

where

$$
A_{n m}=\left\{x_{i}, y_{i}, T y_{i}, S x_{i}, u_{i}, v_{i}: n \leq i \leq m\right\}, \delta\left(A_{n m}\right)=\sup _{x, y \in A_{n m}}\|d(x, y)\|
$$

Then $\left\{x_{n}\right\}$ is called the Ishikawa type iteration process with errors for two generalized asymptotically quasi-nonexpansive mappings $S$ and $T$ in convex cone metric space $(X, d)$.

Remark 2.4. Note that some iteration processes considered in [9, 14, 19, 27] can be obtained from the above process (9) as special cases by choosing suitable spaces and mappings.

In the sequel, we shall need the following lemma.

Lemma 2.1. (see [19]) Let $\left\{a_{n}\right\},\left\{b_{n}\right\}$ and $\left\{\alpha_{n}\right\}$ be sequences of nonnegative real numbers satisfying the inequality

$$
a_{n+1} \leq\left(1+\alpha_{n}\right) a_{n}+b_{n}, \quad n \geq 1 .
$$

If $\sum_{n=1}^{\infty} b_{n}<\infty$ and $\sum_{n=1}^{\infty} \alpha_{n}<\infty$. Then

(a) $\lim _{n \rightarrow \infty} a_{n}$ exists.

(b) If $\liminf _{n \rightarrow \infty} a_{n}=0$, then $\lim _{n \rightarrow \infty} a_{n}=0$. 


\section{Main Results}

Now we give our main results of this paper.

Lemma 3.1. Let $C$ be a nonempty closed convex subset of a complete convex cone metric space $\mathrm{X}, \mathrm{S}, \mathrm{T}: \mathrm{C} \rightarrow \mathrm{C}$ be two generalized asymptotically quasi-nonexpansive mappings with sequences $\left\{r_{n}\right\}$ and $\left\{s_{n}\right\} \in[0, \infty)$ such that $\sum_{n=1}^{\infty} r_{n}<\infty$ and $\sum_{n=1}^{\infty} s_{n}<\infty$. Assume that $F=F(S) \cap F(T) \neq \emptyset$. Let $\left\{x_{n}\right\}$ be the Ishikawa type iteration process with errors defined by (9) and $\left\{u_{n}\right\},\left\{v_{n}\right\}$ satisfying (10) with the restriction $\sum_{n=1}^{\infty}\left(c_{n}+c_{n}^{\prime}\right)<\infty$. Then

(i) there exists a constant vector $v \in P \backslash\{0\}$ such that

$$
\left\|d\left(x_{n+1}, p\right)\right\| \leq k \cdot\left(1+A_{n}\right) \cdot\left\|d\left(x_{n}, p\right)\right\|+k \cdot B_{n}+k \cdot\|v\| \cdot C_{n},
$$

where $A_{n}=r_{n}^{2}+2 r_{n}, B_{n}=\left(2+r_{n}\right) s_{n}$ and $C_{n}=\left(1+r_{n}\right) d\left(u_{n}, p\right)+d\left(v_{n}, p\right)$, for all $n \in \mathbb{N}$ and for all $p \in F$, where $k$ is the normal constant of a cone $P$;

(ii) there exists a real constant $M>0$ such that

$$
\left\|d\left(x_{n+m}, p\right)\right\| \leq \text { k. M. }\left\|d\left(x_{n}, p\right)\right\|+k . M . \sum_{j=n}^{n+m-1} B_{j}+k \cdot M .\|v\| \cdot \sum_{j=n}^{n+m-1} C_{j},
$$

for all $n, m \in \mathbb{N}$ and for all $p \in F$, where $k$ is the normal constant of a cone $P$.

proof. For any $p \in F$, from (7) and (9), we have

$$
\begin{aligned}
d\left(x_{n+1}, p\right) & =d\left(W\left(x_{n}, T^{n} y_{n}, u_{n}, a_{n}, b_{n}, c_{n}\right), p\right) \\
& \preceq a_{n} d\left(x_{n}, p\right)+b_{n} d\left(T^{n} y_{n}, p\right)+c_{n} d\left(u_{n}, p\right) \\
& \preceq a_{n} d\left(x_{n}, p\right)+b_{n}\left[\left(1+r_{n}\right) d\left(y_{n}, p\right)+s_{n}\right]+c_{n} d\left(u_{n}, p\right) \\
& =a_{n} d\left(x_{n}, p\right)+b_{n}\left(1+r_{n}\right) d\left(y_{n}, p\right)+b_{n} s_{n}+c_{n} d\left(u_{n}, p\right) \\
& \preceq a_{n} d\left(x_{n}, p\right)+b_{n}\left(1+r_{n}\right) d\left(y_{n}, p\right)+s_{n}+c_{n} d\left(u_{n}, p\right)
\end{aligned}
$$

and

$$
\begin{aligned}
d\left(y_{n}, p\right) & =d\left(W\left(x_{n}, S^{n} x_{n}, v_{n}, a_{n}^{\prime}, b_{n}^{\prime}, c_{n}^{\prime}\right), p\right) \\
& \preceq a_{n}^{\prime} d\left(x_{n}, p\right)+b_{n}^{\prime} d\left(S^{n} x_{n}, p\right)+c_{n}^{\prime} d\left(v_{n}, p\right) \\
& \preceq a_{n}^{\prime} d\left(x_{n}, p\right)+b_{n}^{\prime}\left[\left(1+r_{n}\right) d\left(x_{n}, p\right)+s_{n}\right]+c_{n}^{\prime} d\left(v_{n}, p\right) \\
& \preceq\left(a_{n}^{\prime}+b_{n}^{\prime}\right)\left(1+r_{n}\right) d\left(x_{n}, p\right)+b_{n}^{\prime} s_{n}+c_{n}^{\prime} d\left(v_{n}, p\right) \\
& =\left(1-c_{n}^{\prime}\right)\left(1+r_{n}\right) d\left(x_{n}, p\right)+b_{n}^{\prime} s_{n}+c_{n}^{\prime} d\left(v_{n}, p\right) \\
& \preceq\left(1+r_{n}\right) d\left(x_{n}, p\right)+s_{n}+c_{n}^{\prime} d\left(v_{n}, p\right) .
\end{aligned}
$$


Substituting (12) into (11), it can be obtained that

$$
\begin{aligned}
d\left(x_{n+1}, p\right) \preceq & a_{n} d\left(x_{n}, p\right)+b_{n}\left(1+r_{n}\right)\left[\left(1+r_{n}\right) d\left(x_{n}, p\right)+s_{n}\right. \\
& \left.+c_{n}^{\prime} d\left(v_{n}, p\right)\right]+s_{n}+c_{n} d\left(u_{n}, p\right) \\
\preceq & \left(a_{n}+b_{n}\right)\left(1+r_{n}\right)^{2} d\left(x_{n}, p\right)+b_{n}\left(1+r_{n}\right) s_{n}+s_{n} \\
& +b_{n} c_{n}^{\prime}\left(1+r_{n}\right) d\left(v_{n}, p\right)+c_{n} d\left(u_{n}, p\right) \\
= & \left(1-c_{n}\right)\left(1+r_{n}\right)^{2} d\left(x_{n}, p\right)+b_{n}\left(1+r_{n}\right) s_{n}+s_{n} \\
& +b_{n} c_{n}^{\prime}\left(1+r_{n}\right) d\left(v_{n}, p\right)+c_{n} d\left(u_{n}, p\right) \\
\preceq & \left(1+r_{n}\right)^{2} d\left(x_{n}, p\right)+\left(2+r_{n}\right) s_{n}+c_{n} d\left(u_{n}, p\right) \\
& +c_{n}^{\prime}\left(1+r_{n}\right) d\left(v_{n}, p\right) \\
\preceq & \left(1+A_{n}\right) d\left(x_{n}, p\right)+B_{n}+v c_{n},
\end{aligned}
$$

where $A_{n}=r_{n}^{2}+2 r_{n}, B_{n}=\left(2+r_{n}\right) s_{n}, C_{n}=c_{n}+c_{n}^{\prime}$ and $v=\left(1+r_{n}\right) d\left(v_{n}, p\right)+d\left(u_{n}, p\right)$. Now, (i) follows from (1), where $\mathrm{k}$ is a normal constant of the cone $\mathrm{P}$.

(ii) It is well known that $1+x \leq e^{x}$ for all $x \geq 0$. Using this, it follows from conclusion (i) that for all $n, m \in \mathbb{N}$ and $p \in F$, we have

$$
\begin{aligned}
& d\left(x_{n+m}, p\right) \preceq\left(1+A_{n+m-1}\right) d\left(x_{n+m-1}, p\right)+B_{n+m-1}+v \cdot C_{n+m-1} \\
& \preceq e^{A_{n+m-1}} d\left(x_{n+m-1}, p\right)+B_{n+m-1}+v \cdot C_{n+m-1} \\
& \preceq e^{A_{n+m-1}\left[e^{A_{n+m-2}} d\left(x_{n+m-2}, p\right)+B_{n+m-2}\right.} \\
& \left.+v \cdot C_{n+m-2}\right]+B_{n+m-1}+v \cdot C_{n+m-1} \\
& \preceq e^{A_{n+m-1}+A_{n+m-2}} d\left(x_{n+m-2}, p\right)+e^{A_{n+m-1}+A_{n+m-2}} \text {. } \\
& {\left[B_{n+m-1}+B_{n+m-1}\right]+e^{A_{n+m-1}+A_{n+m-2}} .} \\
& {\left[C_{n+m-1}+C_{n+m-1}\right] \cdot v} \\
& \preceq M \cdot d\left(x_{n}, p\right)+M \cdot \sum_{j=n}^{n+m-1} B_{j}+M \cdot\left(\sum_{j=n}^{n+m-1} C_{j}\right) \cdot v,
\end{aligned}
$$

where $M=e^{\sum_{j=1}^{\infty} A_{j}}$. Further, (ii) follows from (1), because $P$ is a normal cone with the normal constant $k$.

Theorem 3.1. Let $C$ be a nonempty closed convex subset of a complete convex cone metric space $\mathrm{X}, \mathrm{S}, \mathrm{T}: \mathrm{C} \rightarrow \mathrm{C}$ be two generalized asymptotically quasi-nonexpansive mappings with sequences $\left\{r_{n}\right\}$ and $\left\{s_{n}\right\} \in[0, \infty)$ such that $\sum_{n=1}^{\infty} r_{n}<\infty$ and $\sum_{n=1}^{\infty} s_{n}<\infty$. Assume that $F=$ $\mathrm{F}(\mathrm{S}) \cap \mathrm{F}(\mathrm{T}) \neq \emptyset$. Let $\left\{x_{n}\right\}$ be the Ishikawa type iteration process with errors defined by (9) $\left\{u_{n}\right\},\left\{v_{n}\right\}$ satisfying (10) with the restriction $\sum_{n=1}^{\infty}\left(c_{n}+c_{n}^{\prime}\right)<\infty$. Then $\left\{x_{n}\right\}$ converges to a common fixed 
point of $S$ and $T$ if and only if $\liminf _{n \rightarrow \infty}\left\|d\left(x_{n}, F\right)\right\|=0$, where $\|d(x, F)\|=\inf \{\|d(x, q)\|: q \in F\}$.

proof. The necessity of condition is obvious. Thus, we will only prove the sufficiency. From Lemma 3.1(i), we have

$$
\left\|d\left(x_{n+1}, p\right)\right\| \leq k \cdot\left(1+A_{n}\right) \cdot\left\|d\left(x_{n}, p\right)\right\|+k \cdot B_{n}+k \cdot\|v\| \cdot C_{n},
$$

where $A_{n}=r_{n}^{2}+2 r_{n}, B_{n}=\left(2+r_{n}\right) s_{n}, C_{n}=c_{n}+c_{n}^{\prime}$ and $v=\left(1+r_{n}\right) d\left(u_{n}, p\right)+d\left(v_{n}, p\right)$ with $\sum_{n=1}^{\infty} A_{n}<\infty, \sum_{n=1}^{\infty} B_{n}<\infty$ and $\sum_{n=1}^{\infty} C_{n}<\infty$.

Since $\sum_{n=1}^{\infty} A_{n}<\infty, \sum_{n=1}^{\infty} B_{n}<\infty$ and $\sum_{n=1}^{\infty} C_{n}<\infty$, it follows from Lemma 2.1 that $\lim _{n \rightarrow \infty}\left\|d\left(x_{n}, F\right)\right\|$ exists. According to the hypothesis, $\lim _{n \rightarrow \infty}\left\|d\left(x_{n}, F\right)\right\|=0$, hence we have that $\lim _{n \rightarrow \infty}\left\|d\left(x_{n}, F\right)\right\|=0$.

Next, we show that $\left\{x_{n}\right\}$ is a Cauchy sequence. Let $\varepsilon>0$ be given. There exists an integer $n_{0}$ such that for all $n>n_{0}$, we have

$$
\left\|d\left(x_{n}, F\right)\right\|<\frac{\varepsilon}{6 k^{2} M}, \quad \sum_{n=n_{0}+1}^{\infty} B_{n}<\frac{\varepsilon}{6 k^{2} M}
$$

and

$$
\sum_{n=n_{0}+1}^{\infty} C_{n}<\frac{\varepsilon}{6 k^{2}\|v\| M}
$$

In particular, there exists a $q \in F$ and an integer $n_{1}>n_{0}$ such that

$$
\left\|d\left(x_{n_{1}}, q\right)\right\|<\frac{\varepsilon}{6 k^{2} M} .
$$

It follows from Lemma 3.1(ii) that when $n>n_{1}$, we get

$$
\begin{aligned}
\left\|d\left(x_{n+m}, q\right)\right\|= & \left\|d\left(x_{n_{1}+\left(n+m-n_{1}\right)}, q\right)\right\| \\
\leq & k \cdot M \cdot\left\|d\left(x_{n_{1}}, q\right)\right\|+k \cdot M \cdot\left(\sum_{j=n_{1}}^{n+m-1} B_{j}\right) \\
& + \text { k.M. }\|v\| \cdot\left(\sum_{j=n_{1}}^{n+m-1} C_{j}\right)
\end{aligned}
$$

and 


$$
\begin{aligned}
\left\|d\left(x_{n}, q\right)\right\|= & \left\|d\left(x_{n_{1}+\left(n-n_{1}\right)}, q\right)\right\| \\
\leq & \text { k.M. }\left\|d\left(x_{n_{1}}, q\right)\right\|+k \cdot M \cdot\left(\sum_{j=n_{1}}^{n-1} B_{j}\right) \\
& + \text { k.M. }\|v\| \cdot\left(\sum_{j=n_{1}}^{n-1} C_{j}\right) .
\end{aligned}
$$

Therefore from (11), (15) and (16), we obtain that

$$
\begin{aligned}
\left\|d\left(x_{n+m}, x_{n}\right)\right\| \leq & k \cdot\left\|d\left(x_{n+m}, q\right)+d\left(q, x_{n}\right)\right\| \\
\leq & k \cdot\left\|d\left(x_{n+m}, q\right)\right\|+k \cdot\left\|d\left(q, x_{n}\right)\right\| \\
\leq & 2 k^{2} \cdot M \cdot\left\|d\left(x_{n_{1}}, q\right)\right\|+2 k^{2} \cdot M \cdot\left(\sum_{j=n_{1}}^{n+m-1} B_{j}+\sum_{j=n_{1}}^{n-1} B_{j}\right) \\
& +2 k^{2} \cdot M \cdot\|v\| \cdot\left(\sum_{j=n_{1}}^{n+m-1} C_{j}+\sum_{j=n_{1}}^{n-1} C_{j}\right) \\
\leq & 2 k^{2} \cdot M \cdot\left\|d\left(x_{n_{1}}, q\right)\right\|+2 k^{2} \cdot M \cdot\left(\sum_{j=n_{1}}^{n+m-1} B_{j}\right) \\
& +2 k^{2} \cdot M \cdot\|v\| \cdot\left(\sum_{j=n_{1}}^{n+m-1} C_{j}\right) \\
\leq & 2 k^{2} \cdot M \cdot \frac{\varepsilon}{6 k^{2} M}+2 k^{2} \cdot M \cdot \frac{\varepsilon}{6 k^{2} M} \\
& +2 k^{2} \cdot M \cdot\|v\| \cdot \frac{\varepsilon}{6 k^{2}\|v\| M} \\
= & \varepsilon \cdot
\end{aligned}
$$

Hence $\left\{x_{n}\right\}$ is a Cauchy sequence in closed convex subset $C$ of a complete cone metric space $X$. Therefore, it must be convergent to a point in C. Suppose $\lim _{n \rightarrow \infty} x_{n}=p$. We will prove that $p \in F$.

For a given $\varepsilon>0$, there exists an integer $n_{2}$ such that for all $n \geq n_{2}$, we have

$$
\left\|d\left(x_{n}, p\right)\right\|<\frac{\varepsilon}{2 k\left(2+r_{1}\right)} \text { and }\left\|d\left(x_{n}, F\right)\right\|<\frac{\varepsilon}{4 k\left(2+r_{1}\right)}
$$

In particular, there exists a $p_{1} \in F$ and an integer $n_{3}>n_{2}$ such that

$$
\left\|\mathrm{d}\left(\mathrm{x}_{\mathrm{n}_{3}}, \mathrm{p}_{1}\right)\right\|<\frac{\varepsilon}{2 \mathrm{k}\left(2+\mathrm{r}_{1}\right)}
$$


Then, we have

$$
\begin{aligned}
d(T p, p) \preceq & d\left(T p, p_{1}\right)+d\left(p_{1}, x_{n_{3}}\right)+d\left(x_{n_{3}}, p\right) \\
\preceq & \left(1+r_{1}\right) d\left(p, p_{1}\right)+s_{1}+d\left(p_{1}, x_{n_{3}}\right)+d\left(x_{n_{3}}, p\right) \\
\preceq & \left(1+r_{1}\right) d\left(p, p_{1}\right)+d\left(p_{1}, x_{n_{3}}\right)+d\left(x_{n_{3}}, p\right) \\
\preceq & \left(1+r_{1}\right) d\left(p, x_{n_{3}}\right)+\left(1+r_{1}\right) d\left(x_{n_{3}}, p_{1}\right) \\
& +d\left(p_{1}, x_{n_{3}}\right)+d\left(x_{n_{3}}, p\right) \\
= & \left(2+r_{1}\right) d\left(x_{n_{3}}, p\right)+\left(2+r_{1}\right) d\left(x_{n_{3}}, p_{1}\right)
\end{aligned}
$$

Now using (1), (18) and (19), we obtain

$$
\begin{aligned}
\|\mathrm{d}(\mathrm{T} p, \mathrm{p})\| & \leq \mathrm{k}\left(2+\mathrm{r}_{1}\right)\left\|\mathrm{d}\left(\mathrm{x}_{\mathrm{n}_{3}}, \mathrm{p}\right)\right\|+\mathrm{k}\left(2+\mathrm{r}_{1}\right) \| \mathrm{d}\left(\mathrm{x}_{\left.\mathrm{n}_{3}, p_{1}\right) \|}\right. \\
& <\mathrm{k}\left(2+\mathrm{r}_{1}\right) \cdot \frac{\varepsilon}{2 \mathrm{k}\left(2+\mathrm{r}_{1}\right)}+\mathrm{k}\left(2+\mathrm{r}_{1}\right) \cdot \frac{\varepsilon}{2 \mathrm{k}\left(2+\mathrm{r}_{1}\right)} \\
& =\varepsilon .
\end{aligned}
$$

Similarly, we can also have $\|d(S p, p)\|<\varepsilon$. Since $\varepsilon$ is arbitrary, it follows that $d(T p, p)=d(S p, p)=$ 0 , that is, $p$ is a common fixed point of $S$ and $T$. This completes the proof of Theorem 3.1.

We deduce some results from Theorem 3.1 as follows.

Corollary 3.1. Let $C$ be a nonempty closed convex subset of a complete convex cone metric space $X, S, T: C \rightarrow C$ be asymptotically quasi-nonexpansive mappings with sequence $\left\{r_{n}\right\} \in[0, \infty)$ such that $\sum_{n=1}^{\infty} r_{n}<\infty$. Assume that $F=F(S) \cap F(T) \neq \emptyset$. Let $\left\{x_{n}\right\}$ be the Ishikawa type iteration process with errors defined by (9) and $\left\{u_{n}\right\},\left\{v_{n}\right\}$ satisfying (10) with the restriction $\sum_{n=1}^{\infty}\left(c_{n}+c_{n}^{\prime}\right)<\infty$. Then $\left\{x_{n}\right\}$ converges to a common fixed point of $S$ and $T$ if and only if $\liminf _{n \rightarrow \infty}\left\|d\left(x_{n}, F\right)\right\|=0$, where $\|d(x, F)\|=\inf \{\|d(x, q)\|: q \in F\}$.

proof. It follows from Theorem 3.1 with $s_{n}=0$ for all $n \geq 1$.

Corollary 3.2. Let $C$ be a nonempty closed convex subset of a complete convex cone metric space $X, S, T: C \rightarrow C$ be uniformly quasi-Lipschitzian mappings with $L>0$. Assume that $F=F(S) \cap F(T) \neq \emptyset$. Let $\left\{x_{n}\right\}$ be the Ishikawa type iteration process with errors defined by (9) and $\left\{u_{n}\right\},\left\{v_{n}\right\}$ satisfying (10) with the restriction $\sum_{n=1}^{\infty}\left(c_{n}+c_{n}^{\prime}\right)<\infty$. Then $\left\{x_{n}\right\}$ converges to a common fixed point of $S$ and $T$ if and only if $\liminf _{n \rightarrow \infty}\left\|d\left(x_{n}, F\right)\right\|$ $=0$, where $\|d(x, F)\|=\inf \{\|d(x, q)\|: q \in F\}$.

proof. Since $\left\{r_{n}\right\} \in[0, \infty)$ with $r_{n} \rightarrow 0$ as $n \rightarrow \infty$, then there exists $L>0$ such that $\mathrm{L}=\sup \left\{1+r_{n}: n \geq 1\right\}$. In this case $S$ and $T$ are uniformly quasi-Lipschitzian mappings with 
L > 0. Hence, Corollary 3.2 can be proven by Corollary 3.1 .

Corollary 3.3. Let $C$ be a nonempty closed convex subset of a complete convex cone metric space $X, S, T: C \rightarrow C$ be asymptotically nonexpansive mappings with sequence $\left\{r_{n}\right\} \in[0, \infty)$ such that $\sum_{n=1}^{\infty} r_{n}<\infty$. Assume that $F=F(S) \cap F(T) \neq \emptyset$. Let $\left\{x_{n}\right\}$ be the Ishikawa type iteration process with errors defined by (9) and $\left\{u_{n}\right\},\left\{v_{n}\right\}$ satisfying (10) with the restriction $\sum_{n=1}^{\infty}\left(c_{n}+c_{n}^{\prime}\right)<\infty$. Then $\left\{x_{n}\right\}$ converges to a common fixed point of $S$ and $T$ if and only if $\liminf _{n \rightarrow \infty}\left\|d\left(x_{n}, F\right)\right\|=0$, where $\|d(x, F)\|=\inf \{\|d(x, q)\|: q \in F\}$.

proof. It is clear that an asymptotically nonexpansive mapping must be asymptotically quasinonexpansive. Therefore, Corollary 3.3 can be proven by Corollary 3.1 .

Corollary 3.4. In Corollary 3.1 by setting $E=\mathbb{R}, P=[0, \infty), d(x, y)=|x-y|, x, y \in \mathbb{R}$ (that is $\|\cdot\|=||$.$) , we get Lemma 2$ and Theorem 1,2,3 of [29].

Corollary 3.5. If we set in Corollary $3.1 E=\mathbb{R}, P=[0, \infty), d(x, y)=|x-y|, x, y \in \mathbb{R}$ (that is $\|\|=.||$.$) , we obtain the main result of [4], Theorem 2.1$ and 2.2 of [30] and Theorem 2.1 and Corollary 2.3 of [31].

Remark 3.1. Our results extend the corresponding results of Dukic et al. [8] to the case of more general class of uniformly quasi-Lipschitzian mappings considered in this paper.

Remark 3.2. Our results also extend, improve and generalize many known results from the existing literature.

Example 3.1. Let $E$ be the real line with the usual norm $|$.$| and K=[0,1]$. Define $S, T: K \rightarrow K$ by

$$
T(x)=\frac{x}{2} \sin \left(\frac{1}{x}\right), \quad x \in[0,1],
$$

and

$$
S(x)=\frac{x}{3}, \quad x \in[0,1],
$$

for $x \in K$. Obviously $S(0)=0$ and $T(0)=0$. Hence, $F=F(S) \cap F(T)=\{0\}$, that is, 0 is a common fixed point of $S$ and $T$. Now we check that $S$ and $T$ are generalized asymptotically quasinonexpansive mappings. In fact, if $x \in[0,1]$ and $p=0 \in[0,1]$, then

$$
|T(x)-p|=|T(x)-0|=|(x / 2) \sin (1 / x)-0|=|(x / 2) \sin (1 / x)|
$$




$$
\leq|x / 2| \leq|x|=|x-0|=|x-p|
$$

that is,

$$
|\mathrm{T}(x)-p| \leq|x-p|
$$

Thus, $\mathrm{T}$ is quasi-nonexpansive. It follows that $\mathrm{T}$ is asymptotically quasi-nonexpansive with the constant sequence $\left\{k_{n}\right\}=\{1\}$ for each $n \geq 1$ and hence it is generalized asymptotically quasinonexpansive mapping with constant sequences $\left\{k_{n}\right\}=\{1\}$ and $\left\{s_{n}\right\}=\{0\}$ for each $n \geq 1$. Similarly, we can show that $S$ is also generalized asymptotically quasi-nonexpansive mapping with constant sequences $\left\{k_{n}\right\}=\{1\}$ and $\left\{s_{n}\right\}=\{0\}$ for each $n \geq 1$. But the converse does not hold in general.

$$
\text { Received: March 2012. Accepted: February } 2013 .
$$

\section{References}

[1] M. Abbas and B.E. Rhoades, Fixed and periodic point results in cone metric spaces, Appl. Math. Lett. 22(4)(2009), 511-515.

[2] R.P. Agarwal, D. O'Regan and R. Precup, Domain invariance theorems for contractive type maps, Dynam. Syst. Appl. 16(3)(2007), 579-586.

[3] M. Asadi, H. Soleimani and S.M. Vaezpour, An order on subsets of cone metric spaces and fixed points of set valued contractions, Fixed Point Theory Appl. vol. 2009, Article ID 723203, 8 pages, 2009.

[4] S.C. Bose, Common fixed points of mappings in a uniformly convex Banach space, J. London Math. Soc. 18(1)(1978), 151-156.

[5] S.S. Chang, J.K. Kim and D.S. Jin, Iterative sequences with errors for asymptotically quasinonexpansive type mappings in convex metric spaces, Archives of Inequality and Applications $2(2004), 365-374$.

[6] L.B. Ciric, Generalized contractions and fixed point theorems, Publicationsde l'Institut Mathematique, Nouvelle Serie, 12(26)(1971), 19-26.

[7] K. Deimling, Nonlinear Functional Analysis, Springer, Berlin, Germany, 1985.

[8] D. Dukic, L. Paunovic and S. Radenovic, Convergence of iterates with errors of uniformly quasi-Lipschitzian mappings in cone metric spaces, Krag. J. Math. 35(3)(2011), 399-410.

[9] H. Fukhar-ud-din and S.H. Khan, Convergence of iterates with errors of asymptotically quasinonexpansive mappings and applications, J. Math. Anal. Appl. 328(2007), 821-829.

[10] L.-G. Huang and X. Zhang, Cone metric spaces and fixed point theorems of contractive mappings, J. Math. Anal. Appl. 332(2)(2007), 1468-1476.

[11] D. Ilic and V. Rakocevic, Quasi-contraction on a cone metric space, Appl. Math. Lett. $22(5)(2009), 728-731$. 
[12] S. Imnang and S. Suantai, Common fixed points of multi-step Noor iterations with errors for a finite family of generalized asymptotically quasi-nonexpansive mappings, Abstr. Appl. Anal. (2009), Article ID 728510, 14pp.

[13] S. Jankovic, Z. Kadelburg, S. Radenovic and B.E. Rhoades, Assad-Fixed-Type point theorems for a pair of nonself mappings on cone metric spaces, Fixed Point Theory Appl. vol. 2009, Article ID 761086, 16 pages, doi:10.1155/2009/761086.

[14] J.U. Jeong and S.H. Kim, Weak and strong convergence of the Ishikawa iteration process with errors for two asymptotically nonexpansive mappings, Appl. Math. Comput. 181(2006), 1394-1401.

[15] J.K. Kim, K.H. Kim and K.S. Kim, Convergence theorems of modified three-step iterative sequences with mixed errors for asymptotically quasi-nonexpansive mappings in Banach spaces, PanAmerican Math. Jour. 14(1)(2004), 45-54.

[16] J.K. Kim, K.H. Kim and K.S. Kim, Three-step iterative sequences with errors for asymptotically quasi-nonexpansive mappings in convex metric spaces, Nonlinear Anal. Convex Anal. RIMS Vol. 1365(2004), pp. 156-165.

[17] S.D. Lin, A common fixed point theorem in abstract spaces, Indian J. Pure Appl. Math. $18(8)(1987), 685-690$.

[18] Q.H. Liu, Iterative sequences for asymptotically quasi-nonexpansive mappings, J. Math. Anal. Appl. 259(2001), 1-7.

[19] Q.H. Liu, Iterative sequences for asymptotically quasi-nonexpansive mappings with error member, J. Math. Anal. Appl. 259(2001), 18-24.

[20] G. Petrusel and A. Petrusel, Multivalued contractions of Feng-Liu type in complete gauge spaces, Carpth. J. Math. Anal. Appl. 24(2008), 392-396.

[21] A. Petrusel, Generalized multivalued contractions, Nonlinear Anal. (TMA) 47(1)(2001), 649659 .

[22] S. Radenovic and B.E. Rhoades, Fixed point theorem for two non-self mappings in cone metric spaces, Comput. Math. Appl. 57(2009), 1701-1707.

[23] B. Rzepecki, On fixed point theorems of Maia type, Publicationsde l'Institut Mathematique, Nouvelle Serie, 28(42)(1980), 179-186.

[24] Sh. Rezapour, A review on topological properties of cone metric spaces, in Proceedings of the International Conference on Analysis, Topology and Appl. (ATA 08), Vrinjacka Banja, Serbia, May-June 2008.

[25] Sh. Rezapour and R. Hamlbarani, Some notes on the paper "Cone metric spaces and fixed point theorems of contractive mappings", J. Math. Anal. Appl. 345(2)(2008), 719-724.

[26] W. Takahashi, A convexity in metric space and nonexpansive mappings I, Kodai Math. Sem. Rep. 22(1970), 142-149.

[27] Y.-X. Tian, convergence of an Ishikawa type iterative scheme for asymptotically nonexpansive mappings, Comput. Math. Appl. 49(2005), 1905-1912. 
[28] J. Vandergraft, Newton method for convex operators in partially ordered spaces, SIAM J. Numer. Anal. 4(1967), 406-432.

[29] C. Wang and L. Liu, Convergence theorems for fixed points of uniformly quasi-Lipschitzian mappings in convex metric spaces, Nonlinear Anal. 70(2009), 2067-2071.

[30] C. Wang, J. Zhu, B. Damjanovic and L. Hu, Approximating fixed points of a pair of contractive type mappings in generalized cone metric spaces, Appl. Math. Comput. 215(2009), 1522-1525.

[31] C. Wang, J. Li and D. Zhu, Convergence theorems for the unique common fixed point of a pair of asymptotically nonexpansive mappings in generalized metric spaces, Fixed Point Theory Appl., vol. 2010, Article ID 281890, 6 pages, doi:10.1155/2010/281890.

[32] D. Wardowski, Endpoints and fixed points of set-valued contractions in cone metric spaces, Nonlinear Anal. (TMA) 71(1-2)(2009), 512-516.

[33] P.P. Zabrejko, K-metric and K-normed linear spaces: survey, Collectanea Mathematica 48(46)(1997), 825-859. 